\title{
The Combination of BIM Technology with the Whole Life Cycle of Green Building
}

\author{
Lili Pu, Yueming Wang \\ School of Civil Engineering and Architecture, Southwest University of Science and Technology, Mianyang, China \\ Email: 731957016@qq.com
}

How to cite this paper: $\mathrm{Pu}, \mathrm{L} . \mathrm{L}$. and Wang, Y.M. (2021) The Combination of BIM Technology with the Whole Life Cycle of Green Building. World Journal of Engineering and Technology, 9, 604-613.

https://doi.org/10.4236/wjet.2021.93042

Received: July 24, 2021

Accepted: August 8, 2021

Published: August 11, 2021

Copyright (c) 2021 by author(s) and Scientific Research Publishing Inc. This work is licensed under the Creative Commons Attribution International License (CC BY 4.0).

http://creativecommons.org/licenses/by/4.0/

\begin{abstract}
In the rapid development of modern cities, the construction of green low-carbon livable cities and the realization of energy-saving and beautification of buildings are now being strongly promoted and have become an important indicator of urban development. With the implementation of green building and BIM technology, the combination of BIM technology with green building is a new momentum in the development of the construction industry. The application of BIM can make the quantitative management of green buildings in the whole life cycle, get rid of the shackles of traditional models, make the design and construction process more accurate, and also make the whole process of green buildings more standardized. Among them, the core of BIM is the information model, and the core of green building is: low energy consumption, green and sustainable. This paper firstly explains the concepts and advantages of BIM technology and green building, and separately elaborates the significance of using both in the construction field. Secondly, the current development status of BIM technology and green building is obtained by studying and analyzing the development status and connection between them. Finally, combining BIM technology in the whole life cycle of green building, analyzing the current situation and advantages and disadvantages of using the combination of green building and BIM in actual engineering, clarifying the importance of using BIM in the whole life cycle of green building, and highlighting the combination of BIM technology and the whole life cycle of green building as an important tool for the future development of the construction industry.
\end{abstract}

\section{Keywords}

Green Building, BIM Technology, Life Cycle

\section{Introduction}

Architecture is a habitat for human beings, which can meet the needs of people's 
daily life, and with the improvement of living standards, people's requirements for architecture are getting higher and higher. In recent years, China and relevant governments have issued a large number of documents to encourage the construction of green buildings and promote the development of green industries to meet the requirements of people for both comfortable homes and healthy environments. Compared with traditional buildings, green buildings can provide people with a comfortable and healthy living environment, and also meet the basic national policy of adhering to the harmonious coexistence of man and nature and adhering to the protection of the ecological environment. Adding BIM technology to green building can better improve the quality of building construction and construction efficiency. Through BIM technology to simulate various aspects of the demonstration, the construction staff combined with the results of the demonstration to develop a detailed plan. At the same time, BIM technology can also simulate the construction details during the whole life cycle of the building, which can effectively identify hazards and deficiencies and make changes in time. In addition, BIM technology can also effectively control the construction progress and cost, reduce unnecessary energy consumption in the construction process, ensure that green buildings are more standardized and digitalized in the whole life cycle, realize the concept of green building, and create an atmosphere of harmonious coexistence between people, buildings and the environment. Compared with traditional construction methods, BIM technology can better save construction costs, shorten construction progress, manage the whole construction process in a digital way, and promote the development of the construction industry. The combination of BIM technology and green building has the characteristics of consistency in time dimension. BIM technology is the integrated management of the whole life cycle of project pre-planning, design, construction, operation and maintenance, while the construction of green building also includes the whole life cycle of the building, and the combination of the two makes the time dimension more closely and conveniently. In addition, the combination of BIM technology and green building also has the characteristics of complementary functions. BIM technology can use digital methods to provide core functions such as materials and equipment for green buildings. BIM technology can also provide professional cooperation and coordination at different stages of green building construction, and build a more convenient communication platform for green buildings.

\section{The Concept and Characteristics of Green Building and BIM}

\subsection{Concept of Green Building}

At a simple level, green building is a building project that meets the standards set by the relevant national authorities and is superior than traditional buildings. In a profound sense, it is to create a green and sustainable living environment for people by using reasonable plans and green building materials throughout the con- 
struction period [1]. Compared with traditional buildings, green building is the integration of green environmental protection concepts throughout the life cycle, so that the whole building and the environment as one and to achieve the purpose of protecting the environment. For green building, the goal is to achieve the harmonious coexistence between human and nature in the construction process of the building, to maximize economic benefits while ensuring the conservation of resources and environment, and to reduce the pollution and energy consumption of the environment.

Compared with traditional buildings, green buildings have the advantages of improving people's quality of life, improving natural conditions and effectively controlling pollutant emissions. As early as 1960, an architect proposed the concept of ecological architecture, and in just a few decades, this concept has continued to develop and progress, eventually creating a more complete architectural model [2]. Mainly including in the design process of green building construction planning can reduce the use of building materials to a certain extent, or the use of healthy and environmentally friendly materials and equipment, but also to ensure the overall construction quality of the building, reduce the harm of the building to the surrounding environment, but also can reduce the loss rate of resources to a minimum after the formal use of the building, in order to improve the utilization rate of energy. In addition, green building has the characteristics of saving material energy consumption and protecting the environment. It allows the use of green building materials for construction throughout the construction period and maximizes energy savings. This not only ensures the comfort and safety of the building's interior but also ensures the physical and mental pleasure of the occupants, which is also its most important feature. Overall, green building can promote the continuous improvement and renewal of China's construction industry to a higher level, so as to bringing more comfortable and healthy living environment for residents [3].

\subsection{Concept of BIM Technology}

BIM is the parametric building model, and its core is design visualization. BIM uses computer technology to correlate digital and model with each other to establish 3D building model to simulate the construction process and operational, and ultimately achieving the purpose of design visualization. With this function designers can model design and builders can simulate the construction process, so as to improving the quality of construction. In addition, BIM also provides an effective simulation platform for the exchange of construction information between the front and back of the building construction process, increasing the discussion and friction between all parties to avoid problems in the actual construction. At present, BIM technology has been widely used in most of China's project construction, through the BIM model to depict the entire building, showing the construction process and construction process, while the 3D model will be in accordance with the local design changes to make certain adjustments, so as to realize the efficiency and quality of construction [4]. 


\subsection{Advantages of BIM Technology}

1) Visualization. Visualization of BIM modeling is the ability to create communication and integrity with each component, allowing visualization of all phases of the entire project process. Compared with the traditional mode, the application of BIM technology can make the complex drawings more abstract and threedimensional, and show the content of the drawings in an all-round way, which can make the construction personnel have a clear and definite understanding in the actual operation.

2) Simulation. The simulation of BIM means that the different forms and different operating modes of buildings can be simulated in advance. Through the digital simulation model, a virtual building is constructed. Through which the construction personnel can see the possible problems or effects during the construction process in advance, as well as simulate and rehearse various possible problems to effectively control the construction process.

3) Optimization. BIM technology can be used in project optimization and also in specific projects. When using BIM technology for optimization, many restrictions such as information, time and complexity can be avoided. When using traditional means to optimize, it is difficult to ensure that the results are reasonably optimized, while the use of BIM technology can simplify complex processes and shorten the construction process, greatly reducing the actual workload of construction personnel, thus effectively improving the progress of the project and ensuring the quality of the project [5].

4) Harmonization. BIM technology enables each responsible party to share information through the BIM technology platform in different periods of project progress, and to understand and provide feedback on the engineering work within their responsibility in a timely manner [6]. In the field operation process of construction projects, each project should communicate and give feedback on construction speed and construction process in time, if the construction design or construction process has changed, it is necessary to notify the responsible personnel of each project in time to ensure that the project will not delay the normal construction progress and quality due to the lack of accurate notification of the construction personnel or the different information of various departments in the project implementation process. Therefore, the coordination feature of BIM technology plays an important role in green buildings and plays a role in supervision and management of the construction process [7].

With many features and advantages, the combination of BIM in green building can effectively save resources and reduce energy consumption, for example, when screening construction sites, incorporating BIM technology can screen out the most economical and environmentally friendly construction areas, which can effectively alleviate the current situation of encroaching on a large amount of land resources due to the expanding scale of construction [8]. At the same time, it can also use the characteristics of visualization to supervise and manage the construction site. Through the control of the construction process, the use of field 
materials can be summarized in time, so that no waste of resources and quality assurance can be achieved. In addition, the characteristics of coordination can be used to simulate the shortcomings of the construction in advance, to minimize pollutant emissions and damage to the surrounding environment.

\section{The Development Status and Connection between Green Building and BIM Technology}

\subsection{Research Status of Green Building at Home and Abroad}

With the emergence of the concept of green building, China's construction industry is committed to building green buildings, accelerate the construction of environmental protection and health of the building system, the development to date has achieved significant results. China began to study green building because of the energy issues, which was related to the national conditions of China at that time, and energy saving is the most important point of green building [9]. In recent years, the functional zoning of urban construction is imminent. The shortage of construction resources utilization and the deterioration of ecological environment have restricted the prospect of the construction field. Therefore, green buildings have begun to be loved by architects and have been promoted by leaps and bounds. From preliminary research to comprehensive use, green building in China has a wide prospect of development.

In foreign countries, the view of ecological architecture began in the United States in the 1960s, and thus formed the initial view of green building. Since the 1960s, some architects have incorporated the idea of ecological architecture into their architectural designs, among which the representative ones are cladding architecture, bionic architecture, self-sustaining architecture and metabolic architecture [10], This stage also mainly stays in the theoretical research stage with a rather one-sided approach. In the 1980s, France improved the living environment of some cities; Sweden implemented the "Million Mansions Program" in the process of green building development, and coordinated the construction projects and ecological environment accordingly. Currently, England is building "ecohomes" in line with national conditions; Japan has invented a model for scoring environmental monitoring; and in 2000, Australia introduced a model for rating environmentally healthy buildings in a comprehensive manner [11].

\subsection{Research Status of BIM Technology at Home and Abroad}

By tracing the history, it can be found that the idea of building description system was proposed as early as 1975 , the idea aims to store and view the drawings and methods in the construction process well through technical means, and solving the problems of space occupation and flipping through trivialities, etc. Meanwhile, this idea has promoted the emergence of BIM. As a symbol of the modernization of the construction industry, BIM technology has been favored by many construction enterprises and has become a digital means to replace traditional construction methods. 
In the domestic development: In 2002, China first introduced BIM technology from Autodesk, at that time BIM technology was only as a new means of operation, people lacked a more in-depth exploration and more scientific use of it. Until 2013, China promulgated the Green Building Action Plan [12], more and more architects began to move toward the concept of environmental health. In the continuous research and discussion, BIM technology is also more sophisticated and more and more popular in the field of construction engineering. It has a wide range of application areas, including the design and construction phase, operation and maintenance phase, and has become a necessary tool in the construction process of construction units. Such as the 3D design of buildings, the visualization demonstration of project construction scheme, the regional division of the construction site, the cost estimation, the safety operation drills and other functions are welcomed by major small construction enterprises, which solves various problems they face during the implementation of the project, and improving the technical level and working ability. At the same time, BIM has also become a new discipline for related majors. Colleges and universities organize professional students to conduct research and study, and actually operation the software for modeling. In foreign countries, the United States was the first country to use BIM models throughout the industry and to use BIM most frequently in specific buildings. The entire Western countries is beginning to dabble in this field.

\subsection{The Shortcomings and Significance of Green Building and BIM Technology}

Green building is different from ordinary building construction. It needs to combine the concept of green environmental protection. The most important thing in the construction process is to evaluate and count the building energy consumption. Traditional energy consumption statistics are conducted at the construction drawing stage, and the energy consumption evaluation software may not be applicable to every green building design scheme. BIM technology can advance the energy consumption evaluation of green buildings to the scheme design stage, which is more conducive to timely adjustment of the scheme and make the designed buildings better meet the requirements of environmental protection. In addition the integration of BIM and green building can transform drawings into a three-dimensional model and provide visualization, which enables a more rational selection of feasible solutions and the development of an optimal project cycle. As well as an efficient use of resources, savings in engineering project expenditures, and maximization of the overall benefits of the project solution [13]. The use of BIM technology in the whole life cycle of green buildings can give full play to its advantages, making the main body of the building more information, technology and convenience. Compared with the simple BIM modeling software, it can play its advantages in the actual project and reflect its value. It is no longer just a tool for drawing models, but an effective means to promote the development of the construction industry. 


\section{Application of BIM Technology in the Whole Life Cycle}

BIM technology and green building are both applicable to the whole construction period, not only representing a building part or construction step in the construction process, as shown in Figure 1. This means that the combination of BIM technology and green building in the whole cycle can be very perfect, and BIM technology can be integrated into the whole cycle of green building to play a maximum role. The designed project will adopt BIM supporting model to establish software design 3D components and establish BIM information channel, so that each project responsible party can exchange and communicate data and resources within the channel, which not only ensures the security of data, but also improves the standardization and orderliness of the construction project and enhances the modernization of construction project to better keep up with the times. The combination of BIM, which generally starts from the decision-making phase of building construction and continues to the end of the entire project, can work extremely well with some of the various phases carried out throughout the process, providing project personnel with the convenience of their work. In addition, In addition, the maintenance and disassembly stage of the building can also combine BIM technology to improve efficiency for the whole process, so as to achieve the purpose of green demolition.

\subsection{Application of BIM Technology in Project Planning and Design Stage}

In the stage of social progress, the standards to be achieved by construction projects have become progressively more stringent, and the overall design structure of the project has become progressively more innovative and varied to meet the requirements of users. When constructing a green building, it is important to ensure that the design is reasonable and adequate, that there is an aesthetically pleasing and safe building form, and that the building has an overall structure that meets the specifications [14]. In addition, the overall planning process of the project should also maximize the advantages of green, health and energy saving. In response to the above requirements, BIM technology is appropriately adopted to establish digital models of green buildings and realize high-tech informationization of buildings. Therefore, the integration of BIM technology in the planning and design stage greatly enhances the feasibility and practicality of the construction plan and makes the construction design more perfect and efficient. In addition,

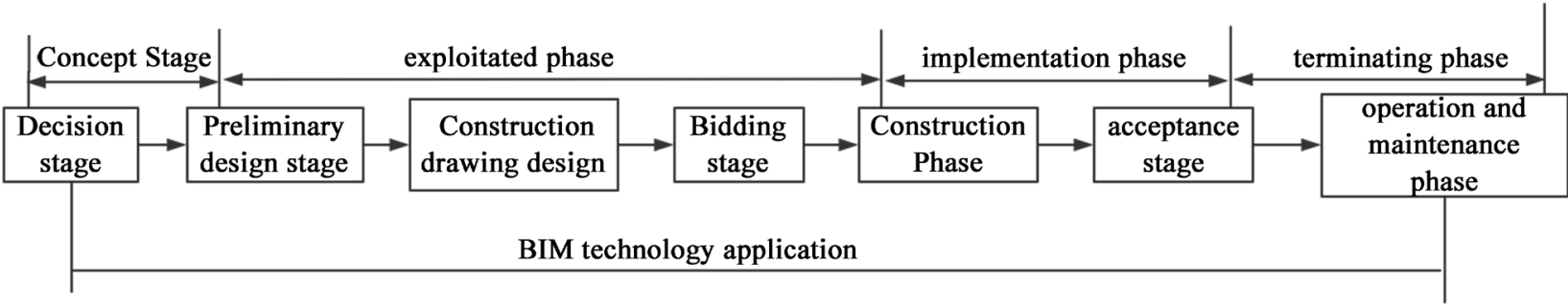

Figure 1. Application of BIM technology in construction process. 
in the stage of project planning and design, the integration of BIM means can also carry out detailed experiments and improvements on the construction design part of the whole project engineering, so as to ensure the feasibility of the whole project. At the same time, the integration of BIM technology can also achieve careful adjustments and changes to various details of the entire design, thus increasing the efficiency of the overall implementation of the project.

We supervise all aspects of the building's exclusion, make analysis in the field, and ensure that the building's environmental construction planning can proceed smoothly by repeatedly comparing and analyzing each element. It is worth noting that the information data should be well summarized and counted when using green technologies for planning, and BIM models should be used to achieve the purpose of integration [15]. The construction site integrated with BIM makes the whole planning stage more orderly, rational and feasible.

Collision overhaul engineering is another advantage of BIM modeling in the planning period. BIM collision overhaul refers to the test overhaul of the functionality and practicality of the building project, which generally includes whether the architectural design is reasonable, whether the overall structure is safe, and whether there is unreasonable planning among the components. The flow of the collision overhaul is shown in Figure 2. Firstly, the three-dimensional model of the building is established by BIM software Revit, and then the established model is imported into Navisworks to confirm the purpose of the collision, develop criteria for discussing collision rules, so as to carry out collision, and obtain collision results after repeated tests and improvements. In this process, the authenticity of the BIM model is used to simulate the actual use process, which can find out the existing problems in a more timely manner and take effective measures to correct them. This also avoids the occurrence of problems such as construction process delay caused by the discovery of loopholes in the actual construction.

\subsection{Application of BIM Technology in Project Construction Stage}

BIM also plays a huge advantage in the construction process. It can simulate and analyze certain key construction links, construction parts and construction sites

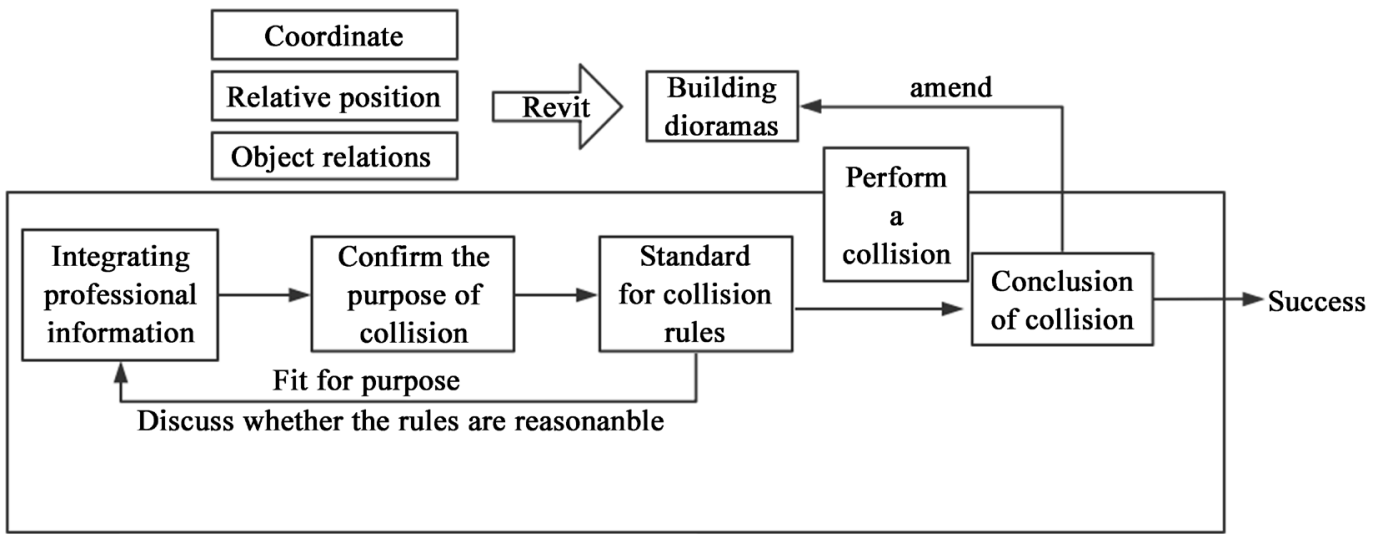

Figure 2. BIM collision detection process. 
[16], find and improve deficiencies in time, fully understand the progress and reality of the whole implementation process, and be able to deal with some problems such as construction project changes and construction process delays. In addition to this, the application of BIM technology can shorten the construction process of green buildings, effectively control construction costs and reduce the risk of cost. By establishing $4 \mathrm{D}$ model, the construction designers combine the buildings with three-dimensional space-time to achieve an expected effect on the whole construction project and realize digital management, so as to effectively and correctly grasp the project process and finally complete the quality and quantity of buildings.

\subsection{Application of BIM Technology in Operation Stage}

The operational stage occupies an important place in the whole life cycle of a green building and professionals must be available to carry out this part of the work. BIM technology used to achieve the optimization and integration of data throughout the operation and management period, through the advantages of cloud space storage and recording, managers can carry out detailed and comprehensive management of green buildings, discover the abnormal situation of buildings in time, and take effective countermeasures and precautions, which can effectively reduce the direct cost loss of construction units. In addition, professionals can also grasp the overall energy use through the BIM model, combined with the actual design of the most appropriate energy consumption plan, but also they can make timely remedial improvements for buildings with large energy consumption, stop damage in time, and achieve the original design intention of green buildings. At the same time, the visualization function of BIM model can also monitor certain parts of the building, such as places that cannot be reached by maintenance personnel or cannot be found through manual inspection, and can carry out timely remediation after discovering the damage points.

\section{Conclusion}

Green building is the new momentum of the future construction industry, is the direction of the construction industry forward. Vigorously promoting the combination of BIM and green building can not only save energy, but also enhance the value, making the main body of the building to maximize the benefits. The application of BIM technology in the whole life cycle of green building can effectively reduce some column problems in green building construction, improve the construction efficiency and reduce the economic cost, which is in line with the current economic development of the construction industry and clarifies the importance of BIM in the future development of the industry. The combination of the two aims to promote the development of the whole field, to maximize the saving of resources and energy consumption based on the existing achievements, to achieve the real sense of green and health, and provide more help for future construction of the city. The combination of BIM technology and green building 
in the future development of the construction industry should become a concept throughout the entire life cycle. At the same time, the efficient collaboration between BIM technology and green building should be strengthened in the future. Many complex technologies should be integrated to make green BIM a construction system, formulate relevant industry norms and standards, and establish corresponding green building evaluation and analysis platform.

\section{Conflicts of Interest}

The authors declare no conflicts of interest regarding the publication of this paper.

\section{References}

[1] Qin, J., Song, Y. and Yu, X. (2019) Application of BIM Technology in Green Building Life Cycle. Communications Science and Technology Heilongjiang, 42, 194-195.

[2] Hua, Y., Li, Z., Wen, Q., Li, X. and Li, Z. (2019) Research on BIM Technology Application Value Measurement Index System in Green Building Operation Phase. Value Engineering, 38, 216-218.

[3] Wang, Y. (2018) Application Strategy of BIM Technology in Green Building Life Cycle. Theoretical Research in Urban Construction, No. 24, 33.

[4] Chen, H. (2020) Application Analysis of BIM Technology in Green Public Building Design. Housing and Real Estate, No. 21, 69.

[5] Liu, Y. (2021) Effective Application of BIM Technology in Green Building Design. Sichuan Cement, 4, 93-94.

[6] Liu, T. (2019) Application of BIM Technology in Green Building Design. Housing and Real Estate, 4, 65.

[7] Zhang, H. (2019) Application of BIM Technology in Green Building Construction Management. Housing and Real Estate, 4, 174.

[8] Zhou, J. (2019) Research on Green Building Construction Management Based on BIM Technology. Construction Materials \& Decoration, No. 6, 38.

[9] Xin, J., Wang, P., Wei, L. and Gao, P. (2019) Analysis of Green Building based on BIM Technology. Housing and Real Estate, No. 6, 38.

[10] Sun, J., Zhang, Y., Sui, J. and Zhou, S. (2008) The Development Analysis of Green Building Assessment System in China and other Countries or Districts. Architecture Technology, No. 1, 63-65.

[11] Liu, J. and Xu, H. (2019) Application Analysis of BIM Technology in Green Building Life Cycle. China Management Informationization, 22, 154-155.

[12] Liang, X. and Deng, T. (2019) Application of BIM Technology in Green Building. Sichuan Cement, No. 3, 92.

[13] Chen, L., Fan, M. and Gong, X. (2019) Application of BIM Technology in Green Building Construction Management. Modern Property Management, 4, 121.

[14] Li, C. (2019) Application of BIM Technology in Green Building Design. Construction Materials \& Decoration, 4, 109-110.

[15] Bu, T. and Lu, Y. (2019) Application of BIM Technology in Green Building Design. Sichuan Building Materials, 45, 47-48.

[16] Wang, P., Xin, J., Wei, L. and Shi, Y. (2019) Research on Green Building Project Management Based on BIM Technology. Housing and Real Estate, No. 3, 110. 